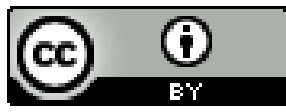

\title{
A IMPORTÂNCIA DA MEMÓRIA PARA A (RE) CONSTRUÇÃO DA IDENTIDADE QUILOMBOLA: A EXPERIÊNCIA DO QUILOMBO DA RUA DE PALHA (ITORORÓ/BA)
}

\author{
Polline Almeida de Oliveira ${ }^{1}$ \\ Ana Cristina Santos Peixoto ${ }^{2}$
}

\begin{abstract}
Resumo: Este artigo procura apresentar o processo de formação histórica da Comunidade Remanescente Quilombola da Rua de Palha, localizada na zona rural do município de Itororó, sul do estado de Bahia, bem como as estratégias de reconfiguração identitária do grupo através do resgate da memória coletiva. Egressos de uma região marcadamente interétnica, esses descendentes de ex-escravizados, constituem um remanescente quilombola contemporâneo no sul baiano com base econômica estabelecida na agricultura de subsistência, portadores de uma regulamentação jurídica que não implicou, necessariamente, numa mudança imediata da noção da identidade que o grupo tem de si. Neste trabalho, apresentamos como a reelaboração da memória coletiva e a construção de novas leituras sobre o passado vêm impactando diretamente o modo pelo qual a Comunidade se vê e auxiliando na (re) construção da sua identidade.
\end{abstract}

Palavras-chave: Comunidade Quilombola da Rua de Palha; Memória; Identidade.

\footnotetext{
${ }^{1}$ Mestre em Ensino e Relações Étnico-raciais pelo Programa de Pós-graduação em Ensino e Relações Étnico-raciais - Universidade Federal do Sul da Bahia (PPGER-UFSB). Professora efetiva de História da Secretaria Estadual de Educação da Bahia. E-mail: polline30@gmail.com

2 Doutora em Linguística e Língua Portuguesa pela Pontifícia Universidade Católica de Minas Gerais (PUC-MINAS) e Mestre em Linguística pela Universidade Federal de Uberlândia (UFU). Professora Adjunta de Língua Portuguesa da Universidade Federal do Sul da Bahia (UFSB) e orientadora de Mestrado Profissional no Programa de Pós-Graduação em Ensino e Relações Étnico Raciais - PPGER- da mesma Universidade. Atua como professora colaboradora no Programa de Pós-Graduação em rede PROFLETRAS - Mestrado Profissional em Letras - na Universidade Estadual de Santa Cruz (UESC). É membro efetiva do Comitê de Acompanhamento de Cotas da UFSB. E-mail: anacris@ufsb.edu.br
}

Revista da ABPN • v. 12, n. Ed. Especial - Caderno Temático: "Africanos, escravizados, libertos biografias, imagens e experiências atlânticas” • agosto de 2020, p. 711-733 


\title{
THE IMPORTANCE OF MEMORY FOR THE (RE) CONSTRUCTION OF QUILOMBOLA IDENTITY: THE EXPERIENCE OF QUILOMBO AT RUA DE PALHA (ITORORÓ/BA)
}

\begin{abstract}
This article seeks to present the historical formation process of the Quilombola Remnant Community of Rua de Palha, located in the rural area of the municipality of Itororó, in the south of the state of Bahia, as well as the strategies of reconfiguring the group's identity through the rescue of collective memory. Coming from a markedly interethnic region, these descendants of ex-slaves constitute a contemporary quilombola remnant in southern Bahia with an economic base established in subsistence agriculture, with legal regulations that did not necessarily imply an immediate change in the notion of identity that the group has it. In this work, we present how the re-elaboration of collective memory and the construction of new readings about the past have directly impacted the way in which the Community sees itself and helping in the (re) construction of its identity.
\end{abstract}

Keywords: Quilombola Community of Rua de Palha; Memory; Identity.

\section{LA IMPORTANCIA DE LA MEMORIA PARA LA (RE) CONSTRUCCIÓN DE LA IDENTIDAD QUILOMBOLA: LA EXPERIENCIA DE QUILOMBO EN LA RUA DE PALHA (ITORORÓ/BA)}

Resumen: Este artículo busca presentar el proceso de formación histórica de la Comunidad Remanente Quilombola de Rua de Palha, ubicada en el área rural del municipio de Itororó, en el sur del estado de Bahía, así como las estrategias de reconfiguración de la identidad del grupo a través del rescate de la memoria colectiva. Provenientes de una región marcadamente interétnica, estos descendientes de ex esclavos constituyen un remanente contemporáneo de quilombolas en el sur de Bahía con una base económica establecida en la agricultura de subsistencia, con regulaciones legales que no necesariamente implican un cambio inmediato en la noción de identidad que El grupo lo tiene. En este trabajo, presentamos cómo la reelaboración de la memoria colectiva y la construcción de nuevas lecturas sobre el pasado han impactado directamente la forma en que la Comunidad se ve a sí misma y ayudando en la (re) construcción de su identidad.

Palabras clave: Comunidad Quilombola de Rua de Palha; Memoria; Identidad.

\section{L'IMPORTANCE DE LA MÉMOIRE POUR LA (RE) CONSTRUCTION DE L'IDENTITÉ QUILOMBOLA: L'EXPÉRIENCE DE QUILOMBO À RUA DE PALHA (ITORORÓ/BA)}

Résumé: Cet article vise à présenter le processus de formation historique de la communauté résiduelle de Quilombola de Rua de Palha, située dans la zone rurale de la municipalité d'Itororó, dans le sud de l'État de Bahia, ainsi que les stratégies de

Revista da ABPN • v. 12, n. Ed. Especial - Caderno Temático: "Africanos, escravizados, libertos biografias, imagens e experiências atlânticas” • agosto de 2020, p. $711-733$ 
reconfiguration de l'identité du groupe à travers le sauvetage de la mémoire collective. Provenant d'une région nettement interethnique, ces descendants d'ex-esclaves constituent un vestige de quilombola contemporain dans le sud de Bahia avec une base économique établie dans l'agriculture de subsistance, avec des réglementations juridiques qui n'impliquaient pas nécessairement un changement immédiat dans la notion d'identité qui le groupe l'a. Dans cet ouvrage, nous présentons comment la réélaboration de la mémoire collective et la construction de nouvelles lectures sur le passé ont eu un impact direct sur la manière dont la Communauté se voit et contribue à la (re) construction de son identité.

Mots clés: Communauté Quilombola de Rua de Palha; Mémoire; Identité.

\section{INTRODUÇÃO}

Como apreendemos com a historiografia, o quilombo foi, em sua origem, o resultado de um movimento social cujo cerne era a resposta combativa de escravizados e grupos subjugados ao sistema opressor e dominante. Em sua concretude, o quilombo foi mais do que isso.

Enquanto fenômeno histórico, o quilombo representou a maior estratégia de sobrevivência ao sistema escravocrata, sempre nos remetendo ao termo resistência. Seja nas abordagens históricas, antropológicas ou sociológicas, a fuga e a vida nos quilombos configuravam as mais relevantes atitudes de objeção utilizadas pelos negros. No entanto, o quilombo não representou apenas esse cenário de tenacidade e afinco, antes foi também um local de produção para o abastecimento das comunidades locais, articulando-se com as lógicas econômicas das regiões onde se estabeleceram e forjando experiências que conectavam todo sistema escravista através de negociações e conflitos.

Este artigo apresenta os resultados de uma pesquisa etno-historiográfica realizada na Comunidade Quilombola da Rua Palha, localizada na zona rural do município de Itororó, sul do estado de Bahia, distante a $18 \mathrm{~km}$ da sede e devidamente certificada como remanescente quilombola pela Fundação Cultural Palmares na data de 18 de abril de 2013.

Nesse recorte espacial, iniciamos no ano de 2016 uma pesquisa que abordou uma discussão acerca da elaboração do conceito de quilombo ao longo do século XX

Revista da ABPN • v. 12, n. Ed. Especial - Caderno Temático: "Africanos, escravizados, libertos biografias, imagens e experiências atlânticas” • agosto de 2020, p. 711-733 
alcançando a ressemantização do termo dentro das recentes perspectivas históricas e antropológicas; investigamos como se deu a formação socioeconômica da região onde a Comunidade da Rua de Palha está inserida; e culminamos com a remontagem da trajetória dos seus moradores, desde o Sertão da Ressaca da Bahia, onde nasceram, até a chegada ao território onde hoje estão situados. Abordamos desde a origem dos fundadores até o processo de autoidentificação e reconhecimento do grupo enquanto remanescente de quilombo.

Observando que as identidades não são fixas, mas construídas politicamente nas experiências e interações de um povo, continuamos a desenvolver a pesquisa no sentido de compreender os efeitos do autorreconhecimento dentro da Comunidade e se ocorreu um processo de fortalecimento identitário. Identificamos que a regulamentação jurídica da identidade do Quilombo da Rua de Palha não implicou necessariamente numa organização política e numa mudança imediata da noção da identidade que o grupo tem de si. Os moradores não se reconheciam 'extraoficialmente' enquanto quilombolas, desconhecendo inclusive o significado do termo.

Justificamos essa constatação com três agravantes que foram identificados: o primeiro é que toda a mobilização e organização para o processo de reconhecimento da Comunidade ocorreu de forma exógena, conduzida pela Secretaria Municipal de Educação de Itororó, não levando em conta a formação das lideranças locais; o segundo é a inexistência de qualquer política pública que tenha favorecido a Comunidade após o processo de reconhecimento, seja na área da infraestrutura ou da educação, visto que a maioria da população não possui a alfabetização primária; o terceiro é a existência de um grande tabu no meio da Comunidade quando se tenta elucidar alguma identificação com a cultura afrobrasileira ou se menciona o tema da escravidão dos antepassados (possivelmente devido ao constrangimento engendrado pela discriminação racial secularmente atrelada aos afrodescendentes). Na realidade, essa identificação acaba por apresentar um sentido pejorativo, denotando aspectos de identidade que os indivíduos têm por indesejáveis. São as marcas incontestes do racismo, nos levando a pensar que são elas as maiores responsáveis por impactar diretamente o modo pelo qual a

Revista da ABPN • v. 12, n. Ed. Especial - Caderno Temático: "Africanos, escravizados, libertos biografias, imagens e experiências atlânticas” • agosto de 2020, p. $711-733$ 
comunidade se vê, impedindo-a de fortalecer-se enquanto comunidade negra representativa dentro do Município de Itororó.

A partir destas identificações, inferimos que a necessidade de se promover a construção de uma 'identidade quilombola' se apresentava enquanto essencial para a recriação do sujeito coletivo e a conferência de consciência política aos moradores da Rua de Palha. Passamos a acreditar que a elaboração desta identidade era pressuposto, fundamento e condição necessária para conferir articulação política ao grupo, e, por meio desta pleitear-se conquistas para toda a coletividade. Presumimos que estes requisitos (construção da identidade quilombola e articulação política da comunidade), possibilitariam ao grupo a percepção de que, desde o reconhecimento, já podiam combater em novas condições enquanto sujeitos portadores de direitos diferenciados.

Desta forma, nossa pesquisa rumou no sentido de desenvolver um produto que contribuísse com a emancipação e o fortalecimento identitário do grupo em questão contemplando dois aspectos: a devolutiva da história pesquisada acerca formação da Comunidade para os seus moradores; e a criação de condições para que as memórias coletivas dos mais velhos pudessem ser resgatas, valorizadas e repassadas dentro daquele espaço.

Com essa ideia, fundamentamos nossa pesquisa nas perspectivas teóricas do Pensamento Decolonial enquanto chave de leitura da realidade complexa dos povos latino-americanos, e redirecionamos o formato do nosso trabalho, deixando de escrever ou pesquisar 'sobre' a perspectiva dos quilombolas e passando a produzir 'com' e 'a partir' dela. Originamos assim, conjuntamente, o $1^{\mathrm{o}}$ Encontro de Memórias Quilombolas da Rua de Palha, com sua primeira edição em 07 de abril de 2019, onde colaboramos com a construção de novas leituras sobre o passado que impactaram diretamente o modo pelo qual a Comunidade se via, e auxiliaram na (re) construção da sua identidade.

\section{O QUILOMBO: CONCEITOS RESSEMANTIZADOS}

Revista da ABPN • v. 12, n. Ed. Especial - Caderno Temático: "Africanos, escravizados, libertos biografias, imagens e experiências atlânticas” • agosto de 2020, p. 711-733 
Para a antropóloga Ilka Boaventura Leite, falar dos quilombos e dos quilombolas na esfera atual é falar de uma luta política e, consequentemente, de uma reflexão científica em processo de construção:

[...] (o quilombo) constitui questão relevante desde os primeiros focos de resistência dos africanos ao escravismo colonial, reaparece no Brasil/república com a Frente Negra Brasileira (1930/40) e retorna à cena política no final dos anos 70, durante a redemocratização do país. Trata-se, portanto, de uma questão persistente, tendo na atualidade importante dimensão na luta dos afrodescendentes. (2000, p. 333).

O conceito que se utiliza atualmente para defini-lo difere fundamentalmente do que representava no transcorrer do regime escravocrata, mesmo quase um século após a abolição da escravidão. O que antes era uma categoria vinculada à criminalidade, marginalidade e banditismo, é hoje considerado, conforme as novas concepções históricas e antropológicas, um ente vivo e dinâmico, um lugar de produção simbólica, sujeito a mudanças culturais.

Cabe ressaltar que a ressemantização do termo 'quilombo' percorreu um longo caminho temporal e discursivo até alcançar o entendimento de que estes grupos correspondem a uma afirmação, concomitantemente, étnica e política. Além de se caracterizarem por processos sociais e políticos específicos que lhes permitem certa autonomia, eles buscam a garantia jurídica da sua territorialidade, cortada pelo vetor étnico.

Nas Ciências Sociais, os argumentos anteriormente utilizados para promover uma definição dessas comunidades, ora de cunho culturalista defendida por antropólogos na década de 1930, ora de perspectiva materialista influenciada por um marxismo estruturalista nos anos 1960 e 1970 no Brasil, não davam mais conta de explicar esse fenômeno. Ao contrário, acabaram produzindo uma ideia da "marginalização" dos quilombos enquanto mundos isolados, ecoando até os dias atuais.

Se até os anos de 1980 a historiografia corrente sobre o assunto definia quilombo como local de negros fugidos da condição de escravos, a partir deste momento essa explicação já não dava mais conta das inúmeras formas de constituição e

Revista da ABPN • v. 12, n. Ed. Especial - Caderno Temático: "Africanos, escravizados, libertos biografias, imagens e experiências atlânticas” • agosto de 2020, p. $711-733$ 
organização de comunidades negras que eclodiram por todo o interior do Brasil (especialmente no período pós-abolição da escravatura, em finais do século XIX).

Vale salientar que é nessa década que se promulga o Art. 68 do Ato das Disposições Constitucionais Transitórias (ADCT) da Constituição Federal de 1988, transformando, de uma só vez, o quilombo histórico em território de importância fundiária, cultural e política. Ao mesmo tempo, transfigurou seus integrantes em sujeitos de direito com a garantia de ocupação desse território. No dispositivo Constitucional passou-se a prever o reconhecimento da propriedade das terras dos remanescentes de comunidades quilombolas e a delinear novas questões relacionadas aos seus direitos. Surgiram novos sujeitos, territórios e ações políticas que visavam a garantia constitucional prevista. $O$ texto aprovado pela Constituinte reconhecia a propriedade definitiva das terras ocupadas por "remanescentes das comunidades de quilombos", devendo o Estado emitir-lhes os títulos.

Com o advento deste aparato legal, introduziu-se uma nova pauta na política nacional: a que requeria que partidos políticos, afrodescendentes, cientistas, intelectuais e militantes fossem convocados a definir o que vem a ser o quilombo e quem são os quilombolas.

Desde então, passou-se a problematizar as complexas dimensões que envolveram as histórias dos quilombos no Brasil. As novas configurações dos grupos em questão exigiam esforços conjuntos e diversificados capazes atribuir uma nova dinâmica ao processo de identificação. Desta forma, passou-se a pensar a condição de remanescente de quilombo enquanto agrupamentos negros não necessariamente originários dos quilombos do período da escravidão, apesar de terem, claramente, suas origens firmadas na constituição de grupos negros campesinos dentro do modo de produção escravista e da abolição no Brasil. Mas, sobretudo, passou-se a identificar o quilombo enquanto um paradigma de força simbólica e política dos segmentos negros brasileiros, fortalecido no período pós-redemocratização.

Para os professores Petrônio Domingues e Flavio Gomes (2013, p. 10):

Revista da ABPN • v. 12, n. Ed. Especial - Caderno Temático: "Africanos, escravizados, libertos biografias, imagens e experiências atlânticas” • agosto de 2020, p. $711-733$ 


\section{0}

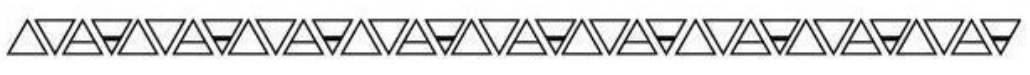

Apropriada em narrativas da memória e transmitida de geração a geração através da oralidade, a ideia de quilombo foi ressignificada como referência histórica fundamental, tornando-se, assim, um símbolo no processo de construção e afirmação social, política, cultural e identitária do movimento negro contemporâneo no Brasil. Se antes o quilombo era visto como resistência ao processo de escravização do negro, a partir dali ele se converteu em símbolo, não só de resistência pretérita, como também de luta no tempo presente pela reafirmação da herança afro-diaspórica e busca de um modelo brasileiro capaz de reforçar a identidade étnica e cultural.

Após uma longa trajetória conceitual (que ainda se encontra em pleno curso), os quilombos passaram a ser conhecidos não só por abrigarem histórias, mas por significarem um processo de trabalho autônomo das comunidades negras, livres da submissão de grandes proprietários. Para além do foco da resistência histórica e da visão estereotipada de grupos isolados, passivos, tribalizados, que buscavam/buscam preservar a tradição de seus antepassados, alcançou-se o entendimento de quilombos sob o viés ressemantizado: grupos étnico-raciais, segundo critérios de autoatribuição, com trajetórias e relações territoriais específicas, apresentando o pressuposto de ancestralidade negra que resistiu/e a todo um histórico de violência.

O Programa Brasil Quilombola, criado pelo Governo Federal no ano de 2004 com o objetivo de implementar diretrizes fundamentais da ação governamental para áreas de remanescentes, assim define o novo conceito de quilombo para fins de direitos e reconhecimento:

São territórios de resistência cultural e deles são remanescentes os grupos étnicos raciais que assim se identificam. Com trajetória própria, dotados de relações territoriais específicas, com presunção de ancestralidade negra relacionada com a luta à opressão histórica sofrida, eles se autodeterminam comunidades negras de quilombos, dados os costumes, as tradições e as condições culturais e econômicas específicas que se distinguem de outros setores da coletividade nacional (BRASIL, 2004, p. 6).

Desta forma, podemos concordar que o próprio termo "remanescente", enquanto noção de resíduo, deixou de corresponder às atuais ideias empregadas pela antropologia, história, órgão estatais e, inclusive, pelos quilombolas ao se autodenominarem. Alfredo Almeida (2005) define o termo "remanescente" como frigorificado e, por isso mesmo,

Revista da ABPN • v. 12, n. Ed. Especial - Caderno Temático: "Africanos, escravizados, libertos biografias, imagens e experiências atlânticas” • agosto de 2020, p. $711-733$ 
uma concepção superada. Para este autor, os 'remanescentes' quilombolas não necessitam, obrigatoriamente, apresentar alguma relação com a definição que a narrativa convencional atribuía aos quilombos. O quilombo ressemantizado é, exatamente, um rompimento com as ideias frigorificadas e com a explicação historicamente cristalizada, se apresentando como grupos sociais que se mobilizam ou são mobilizados por organizações sociais, políticas, religiosas, sindicais, etc. O objetivo destas mobilizações é, sobretudo, o autorreconhecimento e o reconhecimento das suas identidades étnicas e territórios indissociáveis, assim como a asseguração dos seus direitos constitucionais.

\section{HISTÓRIA E TRAJETÓRIA DA COMUNIDADE QUILOMBOLA DA RUA DE PALHA}

A origem da Comunidade da Rua de Palha está relacionada à estrutura social que emergiu a partir da colonização do sertão baiano. Partiu do Sertão da Ressaca da Bahia a família afrodescendente que veio constituir esse espaço habitado, majoritariamente, por pessoas negras.

Analisando os documentos cartoriais e associando às fontes orais através das conversas com os moradores mais antigos, a pesquisa traçou um trajeto de volta desde o local da Comunidade até o Município de Poções-BA, onde encontrou a certidão de casamento do casal fundador, José e Marcionília de Souza Jardim, que ocorreu em $1924^{3}$ no Cartório de Registro Civil das Pessoas Naturais daquela cidade. Através do sobrenome Jardim, identificou alguns dos seus parentes na zona rural de Poções, e por meio do depoimento destes, constatou que a família veio em migração no final do século XIX do Município de Maracás-BA, local onde provavelmente nasceram. A narrativa de seu Lozinho Jardim, sobrinho dos fundadores da Comunidade e morador da Serra do Capa Bode - situada entre os Municípios de Poções e Nova Canaã-BA, foi determinante para essa descoberta: “- Olha, pai me dizia que eles vieram lá de

${ }^{3}$ Certidão de Inteiro Teor, registrada no Cartório do Registro Civil das Pessoas Naturais de Poções sob o n 13831301551924200001076000011913.

Revista da ABPN • v. 12, n. Ed. Especial - Caderno Temático: "Africanos, escravizados, libertos biografias, imagens e experiências atlânticas” • agosto de 2020, p. 711-733 
Maracás, lá de dentro do sertão. Desde menino eu lembro de pai falando isso, que eles tudo nasceram em Maracás”.

A partir destas constatações, aprofundamos nosso estudo acerca da colonização e da chegada dos primeiros negros naquela região sertaneja da Bahia, onde essas cidades estão situadas, especialmente no Sertão da Ressaca que compreende a rota de migração pesquisada.

Observamos que os primeiros africanos e afrodescendentes chegaram às terras sertanejas da Ressaca da Bahia antes mesmo dos colonizadores europeus, se refugiando da escravidão e causando desconforto e preocupação às autoridades coloniais, conforme consta nos primeiros documentos que tratam da exploração deste território. Essa leitura da ocupação negra no sertão baiano anterior à ocupação portuguesa nos permitiu pensar que chegada dos africanos/afrodescendentes e o estabelecimento de relações com os povos nativos que já habitavam a região - os Pataxó, os Kamakã e os Ymboré, contribuíram para a formação de uma região marcadamente interétnica.

Analisando a história de Maracás, identificamos que se trata de um dos mais antigos municípios do sertão baiano, surgindo no processo de interiorização do território do Estado em 1660. Devido às boas pastagens e excelente localização geográfica, ali foi construído um grande e próspero criatório de gado que entrou em pleno declínio entre o final do século XIX e início do século XX (época pós-abolicionista), provocando um quadro de pobreza e evasão pela maioria dos habitantes.

É exatamente no início do século $\mathrm{XX}$, que encontramos os primeiros documentos oficiais sobre a instalação da família Jardim no Município de Poções. As certidões de nascimento dos filhos dos fundadores indicam que José e Marcionília estabeleceram residência na região rural poçoense chamada 'Bananeira' ${ }^{4}$, onde nasceram sete dos seus descendentes: Manoel de Souza Jardim (1913), Sabino de Souza Jardim (1914), Germínia de Souza Jardim (1915), Julia de Souza Jardim (1918), Jorge de Souza Jardim (1920), Damásio de Souza Jardim (1922) e Adriano de Souza Jardim

${ }^{4}$ Certidão de Nascimento de Damásio de Souza Jardim, registrada no Cartório do Registro Civil das Pessoas Naturais de Itororó, Livro A-25, Fls. 03, sob o n ${ }^{\circ}$ 5.123. Certidão de Nascimento de Germínia de Souza Jardim, registrada no Cartório do Registro Civil das Pessoas Naturais de Itororó, Livro A-02, Fls. 299 , sob o no 2396.

Revista da ABPN • v. 12, n. Ed. Especial - Caderno Temático: "Africanos, escravizados, libertos biografias, imagens e experiências atlânticas” • agosto de 2020, p. $711-733$ 
(1927). Os outros dois filhos, Idalina e Joventino de Souza Jardim, já nasceram no novo domicílio da família na Rua de Palha, em Itororó-BA, respectivamente em 1930 e $1932^{5}$. Esses dados nos levaram a inferir que a chegada da família a esta localidade ocorreu por volta da década de 30 em busca de um projeto camponês autônomo estabelecido sob formas tradicionais de cultivo da terra.

Segundo os anciãos locais, a Comunidade recebeu esse nome devido ao material utilizado nas construções ali instaladas pelos primeiros habitantes: casas de pau a pique com telhados de palha. Tal estilo arquitetônico é típico das civilizações africanas interioranas, os bantos, que tinham uma tipologia bem marcante, as cubatas construções de cone sobre um cilindro (mesmo havendo muita variedade de formas) cobertas de palha, também conhecidas como choça de pretos, senzala, palhoça.

Vale destacar que essa arquitetura vernacular africana foi confundida muitas vezes com escassez e pobreza, quando na verdade os povos encontraram as maneiras mais práticas de erguer suas moradas com os recursos naturais que dispunham, construindo em equilíbrio com o meio ambiente.

$\mathrm{Na}$ época da colonização do Brasil, por exemplo, o uso de paredes feitas de pau a pique e tabique foi muito intenso, principalmente no uso de paredes internas de residências da época, revelando uma confluência entre técnicas portuguesas, indígenas e africanas.

As terras da Rua de Palha, onde o casal instalou-se com sua família, possuem 89 hectares e foram adquiridas com labor próprio $^{6}$. Conforme os registros contidos no Sindicato dos Trabalhadores Rurais de Itororó, a gleba dos Jardim foi conquistada por meio de uma titulação de domínio através do Governo do Estado, que consistia em emitir um documento transferindo do patrimônio público para o particular as terras devolutas ocupadas e beneficiadas por pequenos agricultores.

\footnotetext{
${ }^{5}$ Certidão de Nascimento de Idalina de Souza Jardim, registrada no Cartório do Registro Civil das Pessoas Naturais de Itororó, Livro A-14, Fls. 002, sob o no 11.919. Certidão de Nascimento de Joventino de Souza Jardim, registrada no Cartório do Registro Civil das Pessoas Naturais de Itororó, Livro 00025, Fls. 255, RT 0026134.

${ }^{6}$ Certidão dada e passada a pedido verbal pelo Bacharel Ubaldino Brandão, expedida em 02 de abril de 1957 pelo Cartório de Órfãos, Ausentes e Casamentos de Itabuna-BA, livro 4E, sob o nº de ordem 5161, fls. 154.
}

Revista da ABPN • v. 12, n. Ed. Especial - Caderno Temático: "Africanos, escravizados, libertos biografias, imagens e experiências atlânticas” • agosto de 2020, p. $711-733$ 
Inicialmente, a base econômica era o cultivo de plantações de café, cacau e mandioca, conforme consta na certidão do inventário dos bens deixado pelo casal. Importante notar que nessa época (1930) o café passava por um processo de desaceleração na produção industrial em virtude da "Crise de 1929", que atingiu duramente a América Latina e sua economia primário-exportadora. A queda nas exportações de café caiu mais da metade entre 1929 e 1932 e o preço do produto despencou consideravelmente. Por outro lado, nas primeiras décadas do século XX, o cacau era o mais importante produto de exportação da Bahia, fazendo com que vários fazendeiros de origem humilde, além de proprietários de vastas áreas, investissem nas plantações deste fruto. E a terra dos 'Jardim' era geograficamente favorável para essa lavra, permitindo o cultivo do cacau sob a sombra das árvores da Mata Atlântica, seguindo o sistema de "mata cabrucada", como pode ser verificado até os dias atuais.

Com o declínio do café, a família permaneceu na prática da agricultura de subsistência com o cultivo da mandioca e do cacau, o que demonstra adaptação à economia vigente. Mesmo tendo atualmente outras fontes de sustentação, como aposentadorias e bolsas-família, a agricultura familiar e, sobretudo, a cacauicultura ainda representam as atividades de maior importância para a manutenção da Comunidade.

Durante a pesquisa na Rua de Palha, pudemos perceber, além da forma primitiva da plantação, que a mandioca não contribui apenas para a economia local, mas exerce uma função social nas relações de trabalho ao exigir cooperação das pessoas envolvidas durante a produção. A maioria dos moradores complementa suas rendas com a fabricação da farinha e a venda da raiz numa relação familiar de manufatura.

Desde a fundação da Comunidade, a casa de farinha foi uma das primeiras construções, sendo inicialmente erguida com materiais e recursos do próprio ambiente, como argila, cascalho e palhas, de acordo com as informações colhidas entre os moradores.

Há pouco mais de dez anos foi construída uma nova casa de farinha na localidade, através de um convênio firmando entre a Companhia de Desenvolvimento e Ação Regional (CAR), empresa ligada à Secretaria Estadual de Desenvolvimento e

Revista da ABPN • v. 12, n. Ed. Especial - Caderno Temático: "Africanos, escravizados, libertos biografias, imagens e experiências atlânticas” • agosto de 2020, p. $711-733$ 
Integração Regional (SEDIR), e a Associação dos Moradores da Rua de Palha. A ação fez parte do Programa de Combate à Pobreza Rural (PCPR), conhecido na Bahia como 'Produzir'. No entanto, a prática de cultivo, os instrumentos de trabalho e, sobretudo, a forma de cultivar a mandioca utilizados na Rua de Palha são praticamente os mesmos desde quando se empregavam técnicas muito rudimentares, o que resulta num baixo nível de produtividade agrícola. Além do ralador mecânico, os impactos da modernidade ainda não alcançaram os modos de produção da Comunidade, que continuam artesanais na maioria das atividades.

Vale salientar que, apesar do pequeno nível de produção, há legitimidade nos conhecimentos tradicionais aplicados à agricultura, apresentando técnicas de manejo desenvolvidas ao longo de gerações, baseadas no conhecimento sobre a natureza.

Atualmente há 50 famílias morando na região da Rua de Palha, com cerca de 150 habitantes, entre netos, bisnetos e tataranetos do casal José e Marcionília e outros moradores. Convém destacar que o número de habitantes já foi muito maior, mas grande parte acabou migrando para a cidade de Itororó e outras mais distantes em busca de melhores condições de vida, especialmente os mais jovens.

A religião predominante na localidade é a católica, e a maioria das famílias participa das missas e celebrações ocorridas na Capela São Francisco de Assis, que fica situada nas imediações e pertence à Paróquia de Itororó, Diocese de Itabuna. Há alguns anos foi fundada uma congregação da Igreja Assembleia de Deus no local e diversos membros já se converteram à fé protestante.

Quanto à educação, há uma escola ali instalada que recebe o nome do fundador: Escola Municipal José de Souza Jardim. A instituição oferece o Ensino Fundamental das séries iniciais em salas multisseriadas e possui 13 educandos matriculados nesse ano de 20207 . Dispõe de um Projeto Político Pedagógico coletivo que abrange mais quatro Escolas do Campo, mas que não contempla as Diretrizes Curriculares Nacionais para Educação das Relações Étnico-raciais; as Diretrizes Curriculares Nacionais para a Educação Escolar Quilombola; e a Lei Federal 10.639/03,

\footnotetext{
${ }^{7}$ Dado atualizado em 15/02/2020 pela Coordenação das Escolas do Campo da Secretaria Municipal de Educação de Itororó-BA.
}

Revista da ABPN • v. 12, n. Ed. Especial - Caderno Temático: "Africanos, escravizados, libertos biografias, imagens e experiências atlânticas” • agosto de 2020, p. $711-733$ 
que altera a Lei de Diretrizes e Bases da Educação 9.394/96, tornando obrigatório o ensino da História e Cultura Afrobrasileira e Africana no currículo escolar da Educação Básica.

Sabemos que o fator étnico-racial sempre foi o maior responsável por atrair a atenção dos habitantes de Itororó e região para os moradores da Rua de Palha, considerados como excêntricos. No decorrer da pesquisa foi possível identificar que durante o processo de elaboração dos documentos enviados à Fundação Cultural Palmares para o reconhecimento jurídico do grupo no ano de 2011, não foi possível reunir informações entre os moradores, mesmo os mais antigos, acerca da origem da comunidade ou dos seus ascendentes. Desta forma, recorreu-se a um antigo memorialista da região para que elaborasse um histórico daquele coletivo, baseado nas suas próprias recordações ${ }^{8}$. Talvez pelo fato de o memorialista não ter feito parte da comunidade ou desconhecer a verdadeira origem dos fundadores, a história concebida não condiz com a realidade e tampouco foi revista pelos moradores. Se, por um lado, tal relato contribuiu no decurso do reconhecimento jurídico, por outro desfavoreceu um possível processo de resgate da memória, que é uma condição sine qua non para constituir-se o sentimento de identidade. Foi diante desse desafio que a presente pesquisa procurou construir uma outra narrativa histórica que pudesse estar mais próxima da realidade da região e da população que vive ali. Trata-se de uma pesquisa que, com outro olhar histórico, sobretudo sobre as relações étnico-raciais, sobre as origens dos habitantes locais e, ainda, a partir das memórias existentes e resistentes e documentos oficiais, buscou construir uma nova narrativa sobre a história daquela Comunidade.

No tocante à posse da terra, é bastante recorrente, quando se trata de comunidades quilombolas, encontrarmos relatos e estudos de casos sobre os conflitos em relação à titulação da área. Talvez esse seja o fator que mais particulariza as comunidades negras rurais, uma vez que a posse da terra que hoje habitam é o elemento

\footnotetext{
${ }^{8}$ Histórico da Comunidade Quilombola da Rua de Palha escrito pelo Sr. Eduardo Brito de Oliveira e enviado à Fundação Cultural Palmares - FCP.
}

Revista da ABPN • v. 12, n. Ed. Especial - Caderno Temático: "Africanos, escravizados, libertos biografias, imagens e experiências atlânticas” • agosto de 2020, p. 711-733 
fundamental para se entender a formação do grupo e suas estratégias de preservação no espaço territorial (SILVA, 2000).

Na Rua de Palha, não houve esse conflito por território, uma vez que a terra já era titulada antes mesmo do reconhecimento pela Fundação Cultural Palmares. Reiteramos que um dos maiores problemas apresentados na Comunidade é a ausência de organização política e empoderamento étnico dentro da comunidade.

Nesse sentido, as perspectivas teóricas do Pensamento Decolonial trouxeram à pesquisa a inspiração que faltava. Este pensamento trata-se de um movimento de resistência à lógica Modernidade/Colonialidade ${ }^{9}$, de cunho teórico, epistêmico, cultural, prático e político, denunciando e questionando a geopolítica do conhecimento e a Colonialidade do Poder $^{10}$.

A partir das teorias decoloniais, direcionamos nosso trabalho para o seguinte formato: não escrever ou pesquisar sobre a perspectiva subalterna, mas produzir 'com' e 'a partir' dela. Cabe destacar que entendemos a subalternidade conforme a elucidação da autora indiana Gayatri Spivak no seu artigo "Pode o subalterno falar?", que é considerado cânone do pensamento Pós-Colonial. Para essa autora, os subalternos são todos aqueles sobre quem o poder se exerce como abuso; são as camadas mais baixas da sociedade constituídas pelos modos específicos de exclusão dos mercados, da representação política e legal, e da possibilidade de se tornarem membros plenos no estrato social dominante. Não são apenas oprimidos, mas sujeitos e grupos sem

\footnotetext{
${ }^{9}$ A Rede Modernidade/Colonialidade (M/C) se articula desde a década de 1990, a partir de vários encontros e reuniões entre intelectuais de diferentes países da América Latina e de diversas áreas do conhecimento, sendo considerado, portanto, um pensamento transnacional e transdisciplinar, sem se pretender universal. Seus principais expoentes são: Aníbal Quijano; Arturo Escobar; Catherine Walsh; Edgardo Lander; Enrique Dussel; Maldonado Torres; Ramón Grosfoguel; Santiago Castro Gomes; Walter Mignolo. São todos intelectuais cujo Lócus da Enunciação é a América Latina, não apenas como espaço geográfico, mas como um território sócio-político, cultural e epistêmico forjado pelo Colonialismo, no contexto da Diferença Colonial (MIGNOLO, 2003).

${ }^{10}$ No esforço de entender as estratégias de poder subjacentes ao exercício da colonialidade, Quijano (2005; 2010) desenvolveu a ideia de Colonialidade do Poder, como um modelo de exercício da dominação especificamente moderno que interliga a formação racial, o controle do trabalho, o Estado e a produção de conhecimento. Para este autor, a Colonialidade do Poder é a classificação social da população mundial ancorada na noção de raça, que tem origem no caráter colonial, mas já provou ser mais duradoura e estável que o colonialismo histórico, em cuja matriz foi estabelecida.
}

Revista da ABPN • v. 12, n. Ed. Especial - Caderno Temático: "Africanos, escravizados, libertos biografias, imagens e experiências atlânticas” • agosto de 2020, p. $711-733$ 
autonomia, que não participam, ou participam de modo muito limitado, emudecidos pelo imperialismo cultural e pela violência epistemológica (SPIVAK, 2010).

Se as referendadas teorias ocidentais veem os sujeitos subalternizados apenas como objeto de estudo, o Pensamento Decolonial nos permitiu enxergá-los enquanto territórios e sujeitos epistêmicos. Passamos a considerar as epistemologias outras, as concepções que foram subalternizadas, excluídas, omitidas, silenciadas e ignoradas, como uma das formas de conhecimento que, "vindo de baixo, origina uma perspectiva crítica do conhecimento hegemónico nas relações de poder envolvidas" (GROSFOGUEL, 2010, p. 459).

Assim surgiu a ideia de produzirmos junto à Comunidade, no ano de 2019, o $1^{\circ}$ Encontro de Memórias Quilombolas da Rua de Palha, reunindo nossa contribuição de caráter historiográfico (já concluída e que vinha sendo elaborada desde o ano de 2016) e o resgate da memória dos moradores locais. Pensamos que ao narrar-se, os sujeitos provocariam seus depósitos de experiências trazendo à tona tudo o que os constitui para compor uma narrativa de si. Nosso objetivo passou a ser a construção conjunta de um evento com material endógeno, que englobasse as memórias afetivas, autopercepção do território, recursos naturais e histórias, promovendo assim um fortalecimento identitário.

\section{MEMÓRIA E IDENTIDADE: $01^{\circ}$ ENCONTRO DE MEMÓRIAS QUILOMBOLAS DA RUA DE PALHA}

A relação entre Memória e Identidade se dá na medida em que ambas são construções discursivas. Muito mais do que trazer o passado para o presente, rememorar trata-se de um instrumento para reavaliações, revisões, autoanálise e autoconhecimento, sendo o caminho por onde a memória alcança a identidade, se revelando como fator chave em sua (re) construção.

Vale destacar que com a globalização, as identidades se tornaram processos de negociação. Na medida em que foram expostas ao contato com outras culturas,

Revista da ABPN • v. 12, n. Ed. Especial - Caderno Temático: "Africanos, escravizados, libertos biografias, imagens e experiências atlânticas” • agosto de 2020, p. 711-733 
adquiriram características abertas, híbridas, cambiantes e interculturais. Nesse sentido, Hall afirma:

A identidade muda de acordo com a forma como o sujeito é interpelado ou representado, a identificação não é automática, mas pode ser ganhada ou perdida. Ela tornou-se politizada. Esse processo é, às vezes, descrito como constituindo uma mudança de uma política de identidade (de classe) para uma política de diferença (HALL, 2006, p. 21).

Desta forma, é necessário pensar a identidade sob a ótica da provisoriedade, do inacabado, em constante processo de aperfeiçoamento, ou seja, uma obra que nunca se encerra num complexo sistema de interação e articulação com a alteridade.

Partindo das nossas leituras e trabalho de campo desenvolvido na Rua de Palha, verificamos que o processo de (re) construção da identidade poderia estar inscrita em um trabalho de resgate da memória, envolvendo uma reconstituição e reatualização do passado. Surgiu-nos então a ideia de trazer a identidade para o discurso através da memória, permitindo que os sujeitos narrassem a si mesmos.

Pensamos que através de uma construção discursiva da identidade recorrendo à memória, os quilombolas revolveriam o passado para descrever-se, para (re) construir sua identidade, para constituir-se enquanto sujeito diante do outro e posicionar-se dentro do grupo.

Nasceu, portanto, a ideia de promovermos o $1^{\circ}$ Encontro de Memórias da Rua de Palha, representando o elo de ligação entre identidade e memória, e tornando possível a afirmação de Candau de que "a memória é a identidade em ação".

Beatriz Sarlo, em sua obra Tempo passado: cultura da memória e guinada subjetiva (2007), afirma que a memória é o instrumento que permite a atuação do passado no presente por meio das lembranças. Ela pode ser observada como instrumento atuante na reconfiguração das identidades uma vez que possibilita ao sujeito apoderar-se de imagens do passado para consolidar uma nova posição identitária. Em outras palavras, a memória é uma instância reconstituidora do passado e uma das fontes a partir das quais as identidades se edificam.

Revista da ABPN • v. 12, n. Ed. Especial - Caderno Temático: "Africanos, escravizados, libertos biografias, imagens e experiências atlânticas” • agosto de 2020, p. 711-733 
Candau é ainda mais enfático ao dizer que memória e identidade são fenômenos imbricados e amalgamados, que

se entrecruzam indissociáveis, se reforçam mutuamente desde o momento de sua emergência até o momento de sua dissolução. Não há busca identitária sem memória e, inversamente, a busca memorial é sempre acompanhada de um sentimento de identidade, pelo menos individualmente (CANDAU, 2011, p. 19).

Para Pollak, (1989) é comum a narração memorial surgir num momento de tensão, onde há necessidade identificação. Conforme este sociólogo, as narrações de vida ocorrem numa situação de justificação social ou de construção de si mesmo, refazendo discursivamente toda a trajetória do sujeito, guiada por interesses nitidamente identitários:

[as histórias de vida] devem ser consideradas como instrumentos de reconstrução da identidade, e não apenas como relatos factuais. Por definição reconstrução a posteriori, a história de vida ordena acontecimentos que balizaram uma existência. Além disso, ao contarmos nossa vida, em geral tentamos estabelecer uma certa coerência por meio de laços lógicos entre os acontecimentos-chaves (que aparecem então de uma forma cada vez mais solidificada e estereotipada), e de uma continuidade, resultante da ordenação cronológica. Através desse trabalho de reconstrução de si o indivíduo tende a definir seu lugar social e suas relações com os outros (POLLAK, 1989, p. 13).

Diante disso, é inegável afirmar que a memória promove uma revisão autocrítica que interfere na maneira como o indivíduo se percebe, como se mostra aos demais e como se deixa perceber, ou seja, influencia diretamente na forma de identificação do sujeito.

Nesse cenário, em que a memória se faz instrumento de construção identitária, a memória familiar é o primeiro recurso de que o sujeito se vale. Esse é o ambiente em que o indivíduo encontra seus primeiros referentes. A família é o primeiro grupo no qual o sujeito é inserido, por isso é onde inicia sua socialização e as lembranças mais íntimas nascem e são alocadas. É nesse grupo, pois, que o sujeito recebe as primeiras memórias compartilhadas e incorpora em sua bagagem memorial as lembranças herdadas do grupo e vivenciadas com ele, às quais são impregnados sentidos 
identitários. São essas primeiras lembranças que enraízam o sujeito à família e assim surge o sentimento de pertencimento - com relação à comunidade familiar, ao espaço, à cultura e às práticas do grupo. Nasce nesse ambiente a sensação de unidade, quando o sujeito toma consciência de sua individualização, percebendo-se como indivíduo com existência independente e autônoma. É a partir das experiências nesse grupo, portanto, que se produz a consciência das fronteiras que delimitam os sujeitos e os grupos e moldam as identidades.

Neste caminho, acerca da memória familiar, Pollak refere-se à memória herdada: as memórias transmitidas de geração para geração, dentre as quais as familiares são as principais. Essas memórias são, para o autor, as mais importantes fontes de conexão entre memória e identidade:

Se podemos dizer que, em todos os níveis, a memória é um fenômeno construído social e individualmente, quando se trata da memória herdada, podemos também dizer que há uma ligação fenomenológica muito estreita entre a memória e o sentimento de identidade. Aqui o sentimento de identidade está sendo tomado em seu sentido mais superficial, mas que nos basta no momento, que é o sentido da imagem de si, para si e para os outros. Isto é, a imagem que uma pessoa adquire ao longo da vida referente a ela própria, a imagem que ela constrói e apresenta aos outros e a si própria, para acreditar na sua própria representação, mas também para ser percebida da maneira como quer ser percebida pelos outros (POLLAK, 1992, p. 5).

Em suma, a memória familiar se mostra como um dos fatores de união entre memória e identidade por mobilizar as lembranças compartilhadas, nas quais se apoiam os saberes coletivos, as origens comuns e outros referentes. Esse é o princípio do vínculo entre memória e identidade: a consolidação da segunda enraíza-se em processos memoriais e as buscas memoriais em interesses identitários, num fluxo de interação constante. Ambas são produções político-discursivas.

Baseados nestas premissas, imbuídos do Pensamento Decolonial e afetados pelas emoções cativadas durante o convívio com a família Jardim, passamos a desenvolver o projeto do $1^{\circ}$ Encontro de Memórias Quilombolas da Rua de Palha, ocorrido em 07 de abril de 2019. O evento foi dividido em dois momentos: o primeiro ocorreu na sede da Escola Municipal José de Souza Jardim com a devolutiva da história

Revista da ABPN • v. 12, n. Ed. Especial - Caderno Temático: "Africanos, escravizados, libertos biografias, imagens e experiências atlânticas” • agosto de 2020, p. 711-733 
genealógica e trajetória da família Jardim pesquisada durante o período 2016 - 2019, através de slides com mapas e fotografias; e o segundo numa área externa dentro da Comunidade, onde o agrupamento de remanescentes quilombolas recontaram e reviveram suas memórias enquanto protagonistas de sua própria história. O evento permitiu entrecruzar os discursos de cinco gerações, demonstrando como, apesar do contexto de dificuldades e exclusões aos quais foram submetidos durante toda sua trajetória, participaram positivamente da formação da região à qual estão inseridos.

\section{CONCLUSÃO}

Concluímos apontando a maneira pela qual a pesquisa elucidou a importância da recuperação coletiva da história pela perspectiva dos próprios sujeitos pesquisados. Encerramos esta etapa convencidos de algumas ideias fundamentais: primeiramente de que é necessário conhecer a realidade de uma população, sem a qual não é possível contribuir com a reaquisição da sua história. Depois, que esses processos de recuperação coletiva da história insurgem paralelamente às narrativas oficiais e representam a confluência de outros campos de conhecimento. São ações como esta que nos permitem avançar em direção à formulação de propostas que, no campo da memória, incorporem a perspectiva decolonial.

Observamos a importância do estudo da História Regional e Local no universo historiográfico, uma vez que a narrativa deixa de ser fundamentada em temas distantes para se incorporar aos fenômenos históricos da região, e, por consequência, da localidade. Passa a existir a construção de uma história plural, sem qualquer tipo de preconceito, onde as 'minorias' passam a ter vozes.

Usando dessa prerrogativa de valorização das forças macrossociais invisíveis, dos setores populares em suas vidas diárias, lutas e culturas, atravessada pelo compromisso com as trajetórias históricas que até agora foram subalternizadas pelas narrativas oficiais, é que focalizamos a peculiaridade do nosso trabalho.

A forma como presenciamos a emergência de uma narrativa histórica 'outra' e suas memórias correspondentes que foram subalternizadas ou tornadas invisíveis pelos

Revista da ABPN • v. 12, n. Ed. Especial - Caderno Temático: "Africanos, escravizados, libertos biografias, imagens e experiências atlânticas” • agosto de 2020, p. 711-733 
regimes de poder instaurados na América Latina desde o período colonial, procura responder, despretensiosamente, à questão formulada por Spivak: "Pode o subalterno falar?”.

Sabemos que estas metanarrativas da episteme eurocêntrica de caráter estrutural-colonial-racial construíram unilateralmente um conceito de América Latina em detrimento dos saberes e viveres dos seus povos originários e diaspóricos.

O projeto eurocêntrico de tornar hegemônico mundialmente seus paradigmas de vida cotidiana, compreensão da história, ciência e religião acabou produzindo conceitos e categorias pretensamente universais, disseminando um novo padrão mundial de poder. A Europa se apresentou enquanto civilização moderna, superior e desenvolvida, à medida que os demais povos passaram a ser descritos como atrasados, bárbaros e primitivos que necessitavam ser 'resgatados' dessa condição, mesmo que para isso fosse necessária a utilização do genocídio, etnocídio e epistemicídeo.

A história nos mostra que quando a América foi colonizada, houve o encontro com um grande número de diferentes povos, cada um com sua própria história, linguagem, cultura, memórias e identidades. Anos mais tarde, todos eles foram reduzidos a uma única identidade racial, colonial e pejorativa: índios. Da mesma forma ocorreu com os povos trazidos forçadamente do continente africano como escravos, reduzidos à identidade de 'negros'. Todos estes povos foram despojados das suas singularidades e identidades históricas, além de serem reduzidos do seu lugar na história da produção cultural da humanidade.

Diante disso, além de identificar os sujeitos que sempre foram autorizados/desautorizados a falar e constatar que a historiografia tradicional foi contada pelo ponto de vista dos colonizadores, é necessário refutar o silenciamento histórico dos grupos discriminados, a violência imperialista produtora do emudecimento dos subalternos, a história pautada num ponto de vista masculino e branco que Derrida chama de falogocentrismo.

Sabemos que nossa pesquisa e produto final não alteraram imediatamente a noção de identidade que a Comunidade Quilombola da Rua de Palha tem de si, mas decerto foi o pontapé inicial para um processo transformador. Durante a execução do

Revista da ABPN • v. 12, n. Ed. Especial - Caderno Temático: "Africanos, escravizados, libertos biografias, imagens e experiências atlânticas” • agosto de 2020, p. $711-733$ 


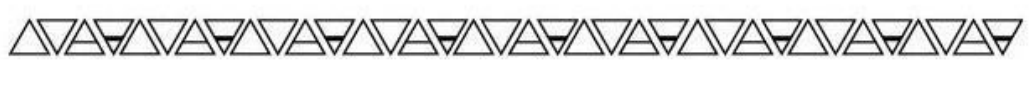

evento foi possível perceber através das falas, dos questionamentos emergidos e das respostas compartilhadas, o princípio de um 'etnoresgate' por meio de situações de reinvenção cultural, que acreditamos ser de fundamental importância para conferir importância afetiva e valorativa àquelas identidades, além de criar condições para a intensificação do sentimento de pertencimento.

Nosso trabalho, desenvolvido dentro de uma pequena comunidade quilombola do sul da Bahia reivindica a legitimidade de narrativas, pensamentos e memórias afrodescendentes-campesinas-quilombolas enquanto territórios de enunciação epistêmica.

Não obstante às marcas profundas da colonialidade, prosseguimos na brecha da cura coletiva da história com um inquietante pensamento crítico de fronteira, buscando e desenvolvendo instrumentos de decolonização intelectual, promovendo rupturas emergentes capazes de combater o pensamento hegemônico desde uma perspectiva do subalterno.

\section{REFERÊNCIAS BIBLIOGRÁFICAS}

ALMEIDA, Alfredo Wagner Berno de. $O$ direito étnico à terra. Orçamento \& Política Socioambiental, Brasília, n. 13, p. 1-12, jun. 2005. Disponível em:< http://www.inesc.org.br/biblioteca/publicacoes/boletins/boletim-orcamento-politicasocioambiental/boletim-socioambientais-e-indigenas-

2005/Boletim\%20SocioAmbientais_13_jun05.pdf>. Acesso em: 06 de abril 2018.

BRASIL. Constituição (1988). Constituição da República Federativa do Brasil. Brasília, DF: Senado Federal: Centro Gráfico, 1988.

Lei $\mathrm{n}^{\circ}$ 9.394, de 20 de dezembro de 1996. Estabelece as diretrizes e bases da educação nacional. Lei de Diretrizes e Bases da Educação - LDB. Brasília, DF, 1996.

Ministério da Educação (MEC). Diretrizes curriculares nacionais para a educação das relações étnico-raciais e para o ensino de História e Cultura Afro-brasileira e Africana. Diário Oficial da União, Brasília, DF, 22 jun. 2004.

2012. Parecer CNE/CEB n ${ }^{\circ} 16$ de 2012. Define diretrizes curriculares nacionais para educação escolar quilombola na educação básica. Diário Oficial da União , Brasília, DF, 20 nov. 2012.

2004. Programa Brasil Quilombola. Secretaria Especial de Políticas de Promoção da Igualdade Racial (Seppir), Brasilia-DF.

CANDAU, Joël. Memória e identidade. Trad. Maria Letícia Ferreira. São Paulo: Contexto, 2011.

Revista da ABPN • v. 12, n. Ed. Especial - Caderno Temático: "Africanos, escravizados, libertos biografias, imagens e experiências atlânticas” • agosto de 2020, p. 711-733 
DOMINGUES, Petrônio; GOMES, Flávio. Histórias Dos Quilombos E Memórias Dos Quilombolas No Brasil: Revisitando Um Diálogo Ausente Na Lei 10.639/031. Revista da Associação Brasileira de Pesquisadores/as Negros/as (ABPN), [S.1.], v. 5, n. 11, p. 05-28, out. 2013. ISSN 2177-2770. Disponível em: <http://abpnrevista.org.br/revista/index.php/revistaabpn1/article/view/187>. Acesso em: 12 jun. 2020 .

GOMES, Flávio. S. Mocambos e quilombos - Uma história do campesinato negro no Brasil. São Paulo: Companhia das Letras, 2015.

GROSFOGUEL, Ramon. Para descolonizar os estudos de economia política e os estudos póscoloniais: transmodernidade, pensamento de fronteira e colonialidade global. In: SANTOS, Boaventura de Souza; Menezes, Maria Paula (Org.). Epistemologias do Sul. Coimbra, Portugal: Cortez, 2010.

HALL, Stuart. A identidade cultural na pós-modernidade. Tradução de Tomáz Tadeu da Silva e Guacira Lopes Louro. Rio de Janeiro: DP\&A. 2006.

Estudos Culturais: dois paradigmas. In: SOVIK, Liv (Org.). Da Diáspora: Identidades e mediações culturais. Belo Horizonte: UFMG/Humanitas, 2006. Cap. 2. p. 123-150.

LEITE, Ilka Boaventura. Quilombos no Brasil. Questões Conceituais e Normativas. NUER / UFSC, v. 7, p. 1-38, 2000.

POLLAK, Michael. Memórias, esquecimento, silêncio. Revista Estudos Históricos, Rio de Janeiro: Ed UFRJ, v. 2, n. 3, p. 3-15, 1989.

Memória e identidade social. Estudos históricos, n. 10, Teoria e História. Rio de Janeiro: Fundação Getúlio Vargas, 1992.

SARLO, Beatriz. Tempo passado: cultura da memória e guinada subjetiva. São Paulo: Companhia das Letras, 2007.

SILVA, Valdélio Santos - 2000 - Rio das Rãs à Luz da Noção de Quilombo. Revista Afro-Ásia, $n^{\circ} .23$. Salvador, EDUFBA, pp. 267-295. Disponível na internet <http://www.lppuerj.net/olped/documentos/ppcor/0210.pdf $>$. Acessado em: 12 de janeiro de 2019.

SPIVAK, Gayatri Chakravorty. Pode o subalterno falar? Tradução de Sandra R. Goulart Almeida; Marcos Feitosa; André Feitosa. Belo Horizonte: Editora UFMG, 2010.

Recebido 03/07/2020

Aprovado em 22/07/2020

Revista da ABPN • v. 12, n. Ed. Especial - Caderno Temático: "Africanos, escravizados, libertos biografias, imagens e experiências atlânticas" • agosto de 2020, p. 711-733 